\title{
Supporting information: Protein paper from exfoliated Eri silk
}

\section{nano fibers}

Yujia Liang ${ }^{l \#}$, Benjamin James Allardyce ${ }^{\text {I\#, Sanjeeb Kalita }}{ }^{1}$, Mohammad Gias Uddin ${ }^{1}$, Sajjad Shafei ${ }^{1}$, Dinidu Perera ${ }^{2}$, Rechana Chandra Nair Remadevi ${ }^{1}$, Sharon L. Redmond ${ }^{3}$, Warren Jeffrey Batchelor ${ }^{4}$, Colin J. Barrow ${ }^{5}$, Rodney J. Dilley ${ }^{3}$, Hannes C. Schniepp ${ }^{2}$, Xungai Wang ${ }^{1}$ and Rangam Rajkhowa ${ }^{1 *}$

${ }^{1}$ Deakin University, Institute for Frontier Materials, Geelong, Victoria 3216, Australia

${ }^{2}$ Department of Applied Science, William \& Mary, Williamsburg, Virginia 23187-8795, United States

${ }^{3}$ Ear Science Institute Australia, Nedlands, Western Australia 6008, Australia

${ }^{4}$ Bioresource Processing Institute of Australia, Department of Chemical Engineering, Monash University, Melbourne Victoria 3800, Australia

${ }^{5}$ Life and Environmental Sciences, Deakin University, Waurn Ponds, VIC 3216, Australia

\# These authors made an equal contribution to this work

* Corresponding author: tel.: +61 35227 3427, email address:

rangam.rajkhowa@deakin.edu.au 


\section{Zeta potential measurement - buffer compositions}

Microfibrillated silk samples were suspended in the following buffers to measure the effect on surface charge at different $\mathrm{pH}$ values.

Table S1: $\mathrm{pH}$ values used for zeta potential experiments, and the buffer used to achieve this $\mathrm{pH}$.

\begin{tabular}{ll}
\hline $\mathbf{p H}$ & Buffer details \\
\hline 3 & Citric acid: $0.0805 \mathrm{M} ; \mathrm{Na}_{2} \mathrm{HPO}_{4}: 0.0195 \mathrm{M}$ \\
5 & Citric acid: $0.0489 \mathrm{M} ; \mathrm{Na}_{2} \mathrm{HPO}_{4}: 0.0511 \mathrm{M}$ \\
7 & Citric acid: $0.0174 \mathrm{M} ; \mathrm{Na}_{2} \mathrm{HPO}_{4}: 0.0826 \mathrm{M}$ \\
9 & $\mathrm{Na}_{2} \mathrm{CO}_{3}: 0.0105 \mathrm{M} ; \mathrm{NaHCO}_{3}: 0.0895 \mathrm{M}$ \\
11 & $\mathrm{Na}_{2} \mathrm{CO}_{3}: 0.087 \mathrm{M} ; \mathrm{NaHCO}_{3}: 0.013 \mathrm{M}$ \\
\hline
\end{tabular}

\section{SEM images on silk solution before and after homogenising.}

SEM Jeol Neoscope (Jeol, USA) at an accelerating voltage of $5 \mathrm{kV}$ was used to observe the morphology of each SNF in suspension (Figure S1). It is obvious that the degummed silk fibres (groups 1, 2, and 3) tend to aggregate before homogenising (Figure S1a, c, and e), which are greatly improved after 5 times homogenisation (Figure S1b, d, and f). However, sample group 4, which was prepared with the most severe degumming condition $\left(120^{\circ} \mathrm{C}, 5 \mathrm{~g} / \mathrm{L}\right)$ seems degrade the original silk fibre and there is no consecutive fibre left both before and after homogenising (Figure S1g h). 

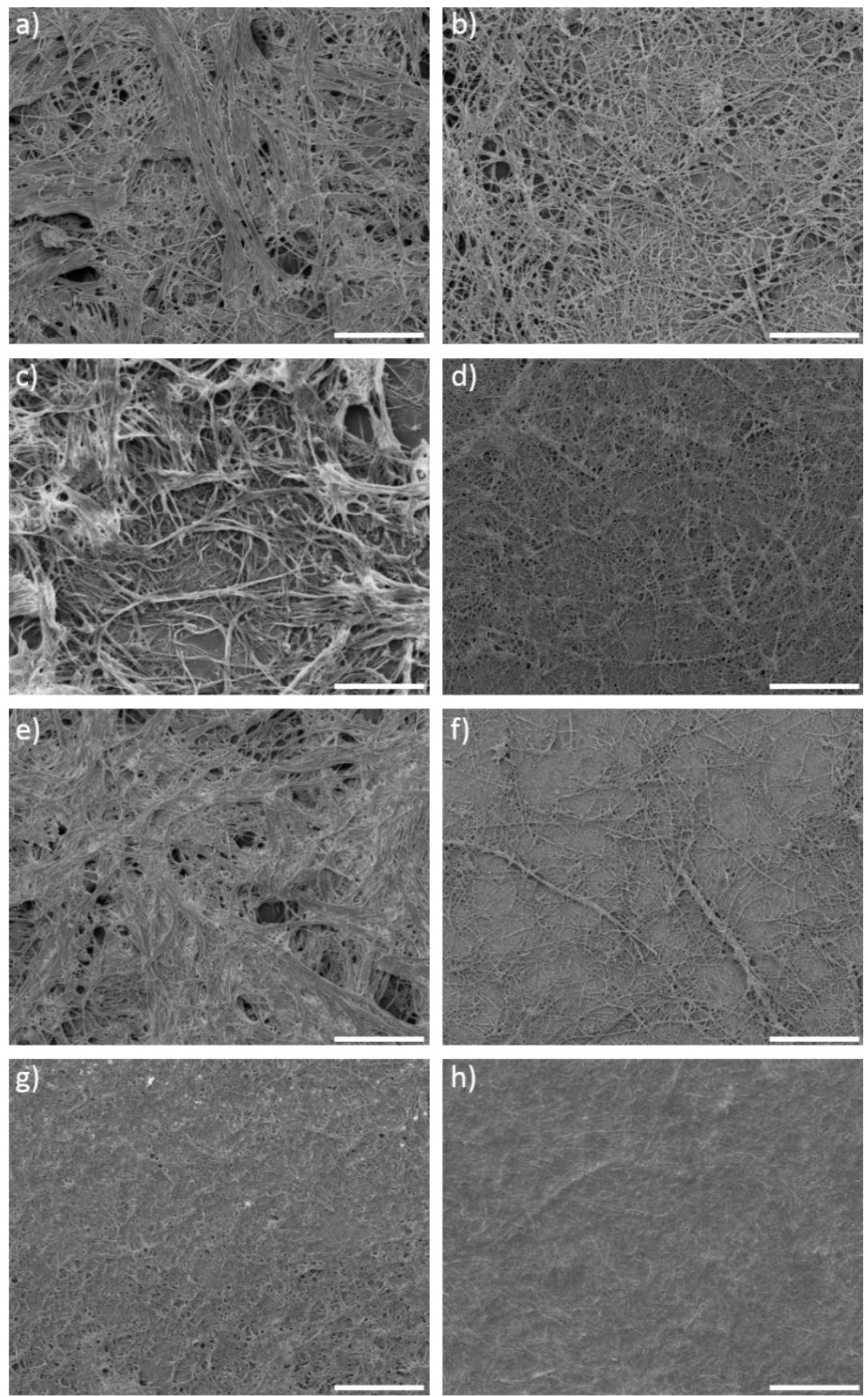

Figure S1: SEM images of the SNF after degumming under different conditions. a) 1M; b) $1 \mathrm{M}+\mathrm{H}$; c) $2 \mathrm{M}$; d) $2 \mathrm{M}+\mathrm{H}$; e) $3 \mathrm{M}$; f) $3 \mathrm{M}+\mathrm{H}$; g) $4 \mathrm{M}$; h) $4 \mathrm{M}+\mathrm{H}$ (Scale bar: $50 \mu \mathrm{m}$ ). 


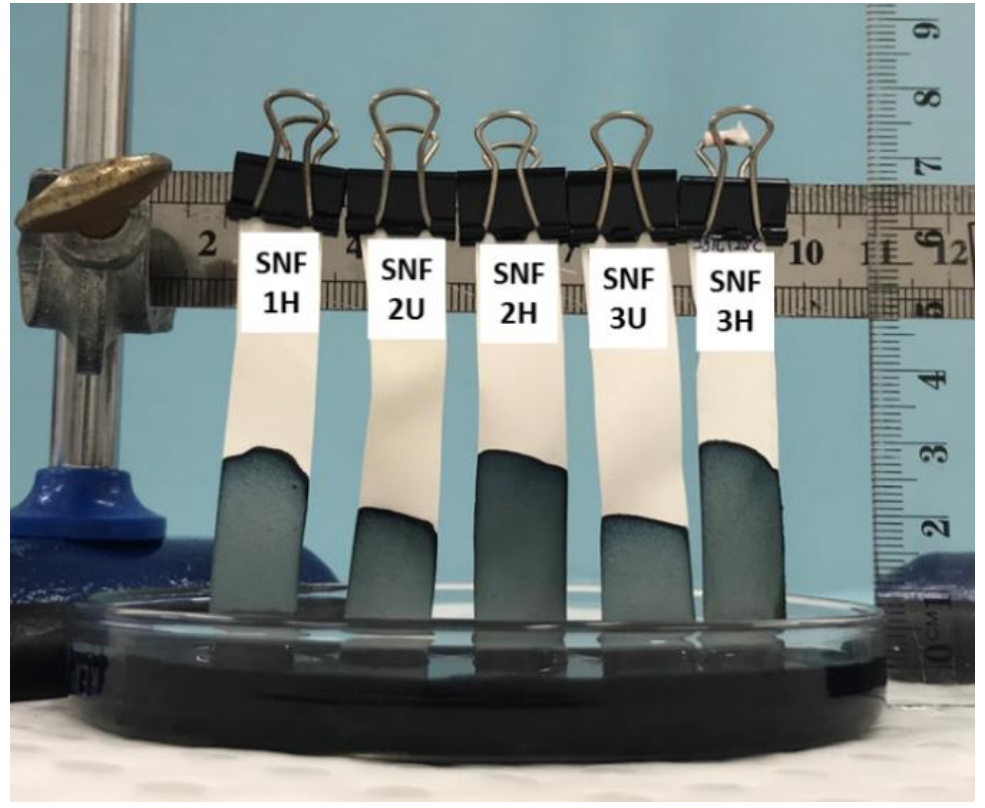

Figure S2: Wick testing on SNF papers 